\title{
Cytological and molecular
} description of Hamiltosporidium tvaerminnensis gen. et sp nov., a microsporidian parasite of Daphnia magna, and establishment of Hamiltosporidium magnivora comb. nov.

\author{
Journal Article \\ Author(s): \\ Haag, Karen Luisa; Larsson, J. I. Ronny; Refardt, Dominik; Ebert, Dieter \\ Publication date: \\ 2011 \\ Permanent link: \\ https://doi.org/10.3929/ethz-b-000033393 \\ Rights / license: \\ In Copyright - Non-Commercial Use Permitted \\ Originally published in: \\ Parasitology 138(4), https://doi.org/10.1017/S0031182010001393
}




\title{
Cytological and molecular description of Hamiltosporidium tvaerminnensis gen. et sp. nov., a microsporidian parasite of Daphnia magna, and establishment of Hamiltosporidium magnivora comb. nov.
}

\author{
KAREN LUISA HAAG ${ }^{1,2}$, J. I. RONNY LARSSON ${ }^{3}$, DOMINIK REFARDT ${ }^{1,4}$ \\ and DIETER EBERT ${ }^{1}$ \\ ${ }^{1}$ University of Basel, Zoological Institute, Vesalgasse 1, 4051 Basel, Switzerland \\ ${ }^{2}$ Programa de Pós-Graduação em Genética e Biologia Molecular, UFRGS, C. Postal 15053, 91501-970 Porto Alegre, \\ Brazil \\ ${ }^{3}$ University of Lund, Department Cell and Organism Biology, Helgonav. 3, S-22362 Lund, Sweden \\ ${ }^{4}$ Institute of Integrative Biology, ETH Zürich, ETH Zentrum CHN 711, Universitätsstrasse 16, CH-8092 Zürich, \\ Switzerland
}

(Received 20 Fanuary 2010; revised 20 April and 22 Fuly 2010; accepted 7 September 2010; first published online 15 October 2010)

S UMMARY

We describe the new microsporidium Hamiltosporidium tvaerminnensis gen. et sp. nov. with an emphasis on its ultrastructural characteristics and phylogenetic position as inferred from the sequence data of SSU rDNA, alpha- and betatubulin. This parasite was previously identified as Octosporea bayeri Jírovec, 1936 and has become a model system to study the ecology, epidemiology, evolution and genomics of microsporidia - host interactions. Here, we present evidence that shows its differences from O. bayeri. Hamiltosporidium tvaerminnensis exclusively infects the adipose tissue, the ovaries and the hypodermis of Daphnia magna and is found only in host populations located in coastal rock pool populations in Finland and Sweden. Merogonial stages of H.tvaerminnensis have isolated nuclei; merozoites are formed by binary fission or by the cleaving of a plasmodium with a small number of nuclei. A sporogonial plasmodium with isolated nuclei yields 8 sporoblasts. Elongated spores are generated by the most finger-like plasmodia. The mature spores are polymorphic in shape and size. Most spores are pyriform $(4 \cdot 9-5 \cdot 6 \times 2 \cdot 2-2 \cdot 3 \mu \mathrm{m})$ and have their polar filament arranged in $12-13$ coils. A second, elongated spore type $(6 \cdot 8-12 \cdot 0 \times 1 \cdot 6-2 \cdot 1 \mu \mathrm{m})$ is rod-shaped with blunt ends and measures $6 \cdot 8-12 \cdot 0 \times 1 \cdot 6-2 \cdot 1 \mu \mathrm{m}$. The envelope of the sporophorous vesicle is thin and fragile, formed at the beginning of the sporogony. Cytological and molecular comparisons with Flabelliforma magnivora, a parasite infecting the same tissues in the same host species, reveal that these two species are very closely related, yet distinct. Moreover, both cytological and molecular data indicate that these species are quite distant from F. montana, the type species of the genus Flabelliforma. We therefore propose that F. magnivora also be placed in Hamiltosporidium gen. nov.

Key words: Ultrastructural characteristics, molecular phylogeny, Octosporea bayeri, Flabelliforma magnivora, Microsporidia, Cladocerca.

\section{INTRODUCTION}

Microsporidia are intracellular obligate parasites that infect many animals. They pose a problem for taxonomy because of their small size and because only a few of their distinct features are microscopically visible (Larsson, 1988, 1999). This problem is further exacerbated by the fact that taxonomists usually have poor material on these species: because many species cannot be bred in the laboratory, available life stages are therefore incomplete. While molecular tools promised to solve this problem, they raised other

* Corresponding author: University of Basel, Zoological Institute, Vesalgasse 1, 4051 Basel, Switzerland. Tel: $\quad+41(0) 612670361 . \quad$ Fax: $\quad+41(0) 612670362$. E-mail: karen.haag@unibas.ch difficulties concerning the correct placement of the entire phylum-and the species within. This is because the extremely derived biological features of microsporidia are mirrored in their DNA sequences (James et al. 2006; Lee et al. 2008), causing spurious results in tree topologies. Here we report on 2 microsporidian species infecting the planktonic crustacean Daphnia magna, Hamiltosporidium tvaerminnensis sp. nov., described in this paper, and Flabelliforma magnivora (Larsson et al. 1998), which has recently been placed in the new genus Neoflabelliforma (Morris and Freeman, 2010). These species show clear differences in their cytology, biogeography, ecology and epidemiology, yet sequence data show that they are very close to each other.

Because $H$. tvaerminnensis sp. nov. resembles the description of Octosporea bayeri Jírovec 1936 in many 
ways, previous publications incorrectly identified it as O. bayeri (see for example Green, 1957, 1974; Ebert et al. 2001; Vizoso and Ebert, 2004; Lass and Ebert, 2006; Altermatt et al. 2007). O. bayeri was described from D. magna from Moravia in the Czech Republic (Jírovec, 1936). The species was never found again in the type locality, neither are there any unambiguous records from other localities. Because $H$. tvaerminnensis sp. nov. has become a model system for the study of microsporidian epidemiology, ecology and evolution (references as above), and because a draft of its genome sequence has recently been published (Corradi et al. 2009), it is imperative to clarify its taxonomic position.

Both F. magnivora (Larsson et al. 1998) and $H$. tvaerminnensis sp. nov. infect the adipose tissue, the hypodermis and the ovaries of the crustacean D. magna (Larsson et al. 1998; Vizoso et al. 2005). Both microsporidian species have been known for some time, but have never been properly compared. $F$. magnivora was placed in the genus Flabelliforma in 1998 based on cytological data. It is typically found in $D$. magna, but was also recorded from $D$. pulex and D. longispina (Stirnadel and Ebert, 1997; Larsson et al. 1998; Decaestecker et al. 2005). It has been recorded from the $\mathrm{UK}$, Belgium and Russia with highly variable prevalences, although usually under 50\% (Mangin et al. 1995; Stirnadel and Ebert, 1997; Larsson et al. 1998; Ebert et al. 2000; Decaestecker et al. 2005). (Note: Mangin et al. (1995), Stirnadel and Ebert (1997) and Ebert et al. (2000) called this species Tuzetia sp.). Recently, due to its molecular divergence to the Flabelliforma-type species, $F$. montana, and a closer relationship to a newly described hyperparasite, Neoflabelliforma aurantiae, it was proposed to reassign $F$. magnivora to Neoflabelliforma (Morris and Freeman, 2010). Here we show that it was appropriate to place $F$. magnivora into a different genus from $F$. montana, but we argue, that it is not close enough to $N$. aurantiae to place it in the genus Neoflabelliforma. Instead we place it in the same genus as $H$. tvaerminnensis sp. nov.

The new species described here exclusively infects D. magna, even where D. magna co-occurs in the same pond with other Daphnia species such as D. pulex and D. longispina (Ebert et al. 2001). Transmission trials in the laboratory further revealed that it cannot be transmitted to clones of D. lumholtzi and $D$. similis, which form the sister-taxon to D. magna (B. Lange and D. Ebert, manuscript in preparation). In addition the new species has never been recorded in places other than D. magna rock pool populations on the islands of the Baltic archipelago of Sweden and Finland (Green, 1957; Ebert et al. 2001; Ebert, 2005). Both field and laboratory studies have shown that D. magna and this species experience a coevolutionary arms race (Ebert, 2008), with hosts rapidly evolving resistance (Zbinden et al. 2008) and parasites showing local adaptation to their natural host populations (Altermatt et al. 2007). H. tvaerminnensis sp. nov. reduces host fecundity by about 20\% (Bieger and Ebert, 2009). To understand the phylogenetic position of this species, the SSU rRNA gene was sequenced and compared to other microsporidia. To our surprise, the sequence was nearly identical to the sequence of $F$. magnivora (Refardt et al.2002). This finding prompted the current study, which seeks to identify the degree of cytological and genetic differentiation between $H$.tvaerminnensis sp. nov. and $F$. magnivora. Table 1 summarizes key aspects of the biology of these species.

\section{MATERIALS AND METHODS}

Infected specimens of Daphnia magna Straus, 1820 were collected from rock pools in Finland (new species) and from ponds in Belgium (F. magnivora). Cultures were established in the laboratory following the procedure of Vizoso and Ebert (2004). Both parasites can be maintained easily in monoclonal D. magna cultures. Vertical transmission to asexual host eggs of both species is $100 \%$, ensuring that the parasite is not lost during host propagation.

\section{Sample preparation for cytology}

Fresh squash preparations of the new species were made according to the agar method of Hostounský and Žižka (1979) and studied using phase-contrast microscopy. Permanent squash preparations were lightly air-dried and fixed either in methanol for at least $15 \mathrm{~min}$ for Giemsa staining, or in BouinDuboscq-Brasil (BDB) solution for at least $1 \mathrm{~h}$ prior to staining with Heidenhain's iron haematoxylin. Whole animals were fixed in BDB solution overnight or longer for paraffin sectioning. Specimens were then washed and dehydrated in a graded series of ethanol, cleared in butanol and embedded in Paraplast (Lancer, St Louis, MO, USA). Sections were cut more or less longitudinally at $10 \mu \mathrm{m}$ and stained with haematoxylin. For details on the histological techniques used, see Romeis (1968). All permanent preparations were mounted in D.P.X. (BDH Chemicals Ltd, Poole, England). Measurements were taken using an image analysis program (MicroMacro AB, Gothenburg, Sweden).

For transmission electron microscopy, hosts infected with the new species were fixed in $2.5 \%(\mathrm{v} / \mathrm{v})$ glutaraldehyde in $0.2 \mathrm{M}$ sodium cacodylate buffer $(\mathrm{pH} 7 \cdot 2)$ at room temperature $\left(18-23^{\circ} \mathrm{C}\right)$ for $24 \mathrm{~h}$. Specimens were then washed in cacodylate buffer and post-fixed in $2 \%(\mathrm{w} / \mathrm{v})$ osmium tetroxide in cacodylate buffer for $90 \mathrm{~min}$ at $4{ }^{\circ} \mathrm{C}$. Following this, they were washed and dehydrated in an ascending series of buffer-acetone solutions to absolute acetone and then embedded in Epon. Sections were stained using uranyl acetate and lead citrate (Reynolds, 1963). 
Table 1. Comparison of Octosporea bayeri Jirovec 1936, Flabelliforma magnivora Larsson et al. 1998 and the new species described here

(The table was compiled from Jirovec, 1936; Mangin et al. 1995; Stirnadel and Ebert, 1997; Larsson et al. 1998; Ebert, 2005; Lass and Ebert, 2006.)

\begin{tabular}{|c|c|c|c|}
\hline Trait & Octosporea bayeri & Flabelliforma magnivora & Hamiltosporidium tvaerminnensis \\
\hline $\begin{array}{l}\text { Recorded Daphnia } \\
\text { host species, } \\
\text { (excluded hosts) }\end{array}$ & D. magna & $\begin{array}{l}\text { D. magna, D. longispina, } \\
\text { D. pulex }\end{array}$ & $\begin{array}{l}\text { D. magna (D. longispina, D. pulex, } \\
\text { D. lumholtzi, D. similis) }\end{array}$ \\
\hline Infected tissue & Adipose tissue & $\begin{array}{l}\text { Adipose tissue, hypodermis, } \\
\text { ovaries }\end{array}$ & Adipose tissue, hypodermis, ovaries \\
\hline Transmission & Unknown & $\begin{array}{l}\text { Transovarial, horizontal via } \\
\text { second host was suggested } \\
\text { (Mangin } \text { et al. 1995) }\end{array}$ & Transovarial and horizontal \\
\hline $\begin{array}{l}\text { Reported } \\
\text { geographical } \\
\text { distribution }\end{array}$ & Moravia, Czech Republic & England, Belgium, Russia & $\begin{array}{l}\text { Finland, Sweden, Skerry Islands of the } \\
\text { Baltic Sea }\end{array}$ \\
\hline $\begin{array}{l}\text { Habitat of host } \\
\text { population }\end{array}$ & Large pond & Permanent ponds & Intermittent coastal rock pools \\
\hline $\begin{array}{l}\text { Mature pyriform } \\
\text { spore type } \\
\text { (measurements for } \\
\text { fresh spores) }\end{array}$ & Not observed & $\begin{array}{l}\text { Pyriform with blunt ends, } \\
\text { one side slightly convex, } \\
4 \cdot 07-4 \cdot 93 \times 2 \cdot 34-3 \cdot 03 \mu \mathrm{m}\end{array}$ & $\begin{array}{l}\text { Pyriform with blunt ends, sides convex } \\
\text { and concave, slightly bent, } 4 \cdot 9- \\
5 \cdot 6 \times 2 \cdot 2-2 \cdot 3 \mu \mathrm{m}\end{array}$ \\
\hline $\begin{array}{l}\text { Mature elongated } \\
\text { spore type } \\
\text { (measurements for } \\
\text { fresh spores) }\end{array}$ & $\begin{array}{l}\text { Elongated, rod-like with } \\
\text { blunt ends, posterior } \\
\text { end wider, straight or } \\
\text { slightly curved, } 5 \cdot 5- \\
9 \times 1 \cdot 5-2 \cdot 5 \mu \mathrm{m}\end{array}$ & Not observed & $\begin{array}{l}\text { Elongated, rod like with blunt ends, } \\
\text { posterior end wider, straight or slightly } \\
\text { curved, } 6 \cdot 8-12 \cdot 0 \times 1 \cdot 6-2 \cdot 1 \mu \mathrm{m}\end{array}$ \\
\hline $\begin{array}{l}\text { Octosporous spore } \\
\text { groups }\end{array}$ & Not observed & Not observed & Observed \\
\hline
\end{tabular}

\section{DNA samples, PCR and sequencing}

Parasite DNA samples were obtained from naturally infected D. magna individuals maintained in the laboratory. A draft of the H.tvaerminnensis genome (isolate OER-3-3) was obtained by shotgun sequencing using Illumina ${ }^{\mathrm{TM}}$ sequencing (Solexa, Fasteris SA, Geneva, Switzerland). From 35 bp reads with the Illumina Genome Analyzer ${ }^{\mathrm{TM}}$, we acquired $898 \mathrm{Mb}$ of DNA sequence, yielding about $34 \cdot 2-$ $37 \cdot 2 \times$ coverage of the genome (the genome size is estimated at $24 \mathrm{Mb}$ ). Reads were assembled into 41804 contigs, amounting to $13 \cdot 3 \mathrm{Mb}$ of sequence data. The length of contigs averaged $320 \mathrm{bp}$, with a range from $100 \mathrm{bp}$ to $8 \mathrm{~kb}$ (for details see Corradi et al. 2009). The contigs were searched (BLASTN) for sequences that could be used as markers to analyse phylogeny (alpha and beta tubulins, SSU rDNA). The following primers were designed for amplifying the tubulin genes of $F$. magnivora: alphatub-F TATGCTCGAGGCCATTATAC, alphatub-R CAAATGCACGTTTAGCAAAC, betatub-F CAATATGTTCCTCGAGCTGT and betatub-R ACCATCATATT'TCT'TGCATCG. All PCR reactions were performed in a volume of $50 \mu$ l containing $1 \cdot 25 \mathrm{U}$ of $\mathrm{Taq}$ Polymerase (Sigma), $1 \mathrm{X}$ reaction buffer, $1.5 \mathrm{~mm} \mathrm{MgCl}_{2}$, $20 \mathrm{pmol}$ of each primer (Microsynth), $200 \mu \mathrm{M} \mathrm{dNTP}$ and 100-500 ng of template DNA. The PCR profile consisted of an initial denaturation step at $95^{\circ} \mathrm{C}$ for $5 \mathrm{~min}$, over $35 \mathrm{am}$ plification cycles (annealing at $50^{\circ} \mathrm{C}$ for $30 \mathrm{~s}$, extension at $72^{\circ} \mathrm{C}$ for $60 \mathrm{~s}$, denaturation at $95^{\circ} \mathrm{C}$ for $30 \mathrm{~s}$ ) and a final extension at $72{ }^{\circ} \mathrm{C}$ for $5 \mathrm{~min}$. Amplicons were column purified (Sigma) and sequenced directly (Macrogen, Seoul, South Korea).

\section{Phylogeny reconstructions}

To evaluate the phylogenetic relationship between the new species and $F$. magnivora, we first compared their partial sequences for alpha-tubulins (369 aa), beta-tubulins (233 aa) and SSU rDNA (1464 nt) with 8 representative microsporidian species, using Saccharomyces cerevisiae as an outgroup. Agmasoma penaei and Flabelliforma montana, which share ultrastructural features with the species described here, are not included in this phylogeny because their alpha- and beta-tubulin sequences are unknown. Thus, we used only SSU rDNA sequences (1082 nt) from another group of closely related microsporidians to evaluate their relatedness to $F$. magnivora and to the species described here, using Glugea plecoglossi as outgroup. GenBank Accession nos. for all sequences used are provided in Table 2. Sequences were first assembled with CodonCode Aligner (version 3.0.2) to define regions of overlap. Nucleotide sequences for alpha and beta-tubulins were translated 
Table 2. GenBank Accession codes for the sequences used in the phylogeny inferences

\begin{tabular}{llll}
\hline \hline & Alpha-tubulin & Beta-tubulin & SSU rDNA \\
\hline Glugea plecoglossi & AY138804 & AF162084 & AJ295326 \\
Brachiola algerae & EU625354 & EU625355 & AY230191 \\
Encephalitozoon cuniculi & NM_001041670 & AL590443 & L17072 \\
Nosema bombycis & DQ091252 & EF025915 & L39111 \\
Antonospora locustae & U66907 & AY138803 & AY376351 \\
Spraguea lophii & U66906 & AF162082 & AF033197 \\
Trachipleistophora hominis & AY138781 & AF162081 & AJ002605 \\
Saccharomyces cerevisiae & NP_013625 & NP_116616 & gi_85666119:455934-457733 \\
Hamiltosporidium tvaerminnensis sp.nov. & GQ496300 & GQ853827 & GQ843833 \\
Flabelliforma magnivora (Belgium) & GQ496301 & GQ843828 & AJ302319 \\
F. magnivora (England) & - & - & AY649786 \\
F. magnivora Russia) & - & - & AJ302318 \\
Flabelliforma montana & - & - & AJ252962 \\
Agmasoma penaei & - & - & DQ342240 \\
Neoflabelliforma aurantiae & - & - & AY230191 \\
Glugea atherinae & - & - & U15987 \\
Paratelohania anophelis & - & - & AF027682 \\
Amblyospora sp & - & - & AJ252949 \\
Gurleya vavrai & - & - & AF394526 \\
Larssonia obtusa & - & - & AF027683 \\
Culicosporella lunata & - & - & U68473 \\
Amblyospora californica & - & AF027684 \\
Edhazardia aedis & & & \\
\hline \hline
\end{tabular}

into proteins. The overlapping protein/gene regions were then aligned using default settings in Clustal X software (Thompson et al. 1997). SSU rDNA alignment regions with large gaps were excluded. In the first analysis aligned sequences for the 3 markers were concatenated and used as a partitioned dataset for phylogeny reconstruction with MrBayes 3.1 (Ronquist and Huelsenbeck, 2003). Both analyses ran for 100000 generations, sampling every 100th generation, using a mixture of models with fixed-rate matrices for the amino acid partitions and the $\mathrm{GTR}+\mathrm{G}+\mathrm{I}$ model for the SSU rDNA. Amino acid changes observed along the main branches of this tree were tracked, based on parsimony, using MacClade 4.08.

\section{RESULTS}

\section{Pathogenicity and transmission}

Although H. tvaerminnensis sp. nov. primarily invaded the adipose tissue of its host, infection was also found in the hypodermis and ovaries (Fig. 1A). The infected tissue degraded into a syncytium filled with microsporidia (Fig. 1B); in the late stages of infection, the only distinct remnants of host tissue were mitochondria dispersed among the developing microsporidia (Fig. 1B). In advanced infections, the most immature stages of the microsporidia were concentrated at the periphery (Fig. 1B). The parasite's effect on its host has already been documented (Vizoso and Ebert, 2005; Bieger and Ebert, 2009). Transmission is both transovarial and horizontal (Vizoso et al. 2005). The latter occurs when sporeswhich can survive extended periods in the environment-are released from decaying cadavers (Lass and Ebert, 2006).

\section{Pre-sporal stages and life cycle}

Early stages of vegetative reproduction (merogony) were rare in light microscopic preparations, and our evaluation, including measurements, is based on ultrathin sections. Meronts and merozoites were seen as either elongated or rounded cells in direct contact with the cytoplasm of the host cell (Fig. 1C). Elongated meronts measured up to $6 \cdot 2 \mu \mathrm{m}$ in length in sections, and rounded merozoites (Fig. 1C) measured up to $3 \cdot 8 \mu \mathrm{m}$ in diameter. Merogonial stages were delimited by a thick plasma membrane, about $9 \mathrm{~nm}$, without external reinforcements (Fig. 1C). The elongated stages and most rounded stages showed 2 nuclei that measured $1 \cdot 6-2 \cdot 5 \mu \mathrm{m}$ in diameter in sections (Fig. 1C, E). These coupled nuclei were interpreted as dividing stages, not as diplokarya. Large quantities of free ribosomes made the cytoplasm uniformly and densely granular (Fig. 1C). Nuclei had a similar density, although the granules were smaller. A large prominent nucleolus was often visible (Fig. 1D). Vegetative reproduction occurred by binary fission or by the fragmentation of plasmodia with a small number of nuclei (4 nuclei were observed) (Fig. 1E). The last generation of merozoites that matured to sporonts was often seen in chain-like arrangements (Fig. 1B, D).

The first sign of onset of sporogony was the secretion of a thin envelope, the primordium of the sporophorous vesicle, approximately as thick as the plasma membrane (Fig. 2A). The primordia were 


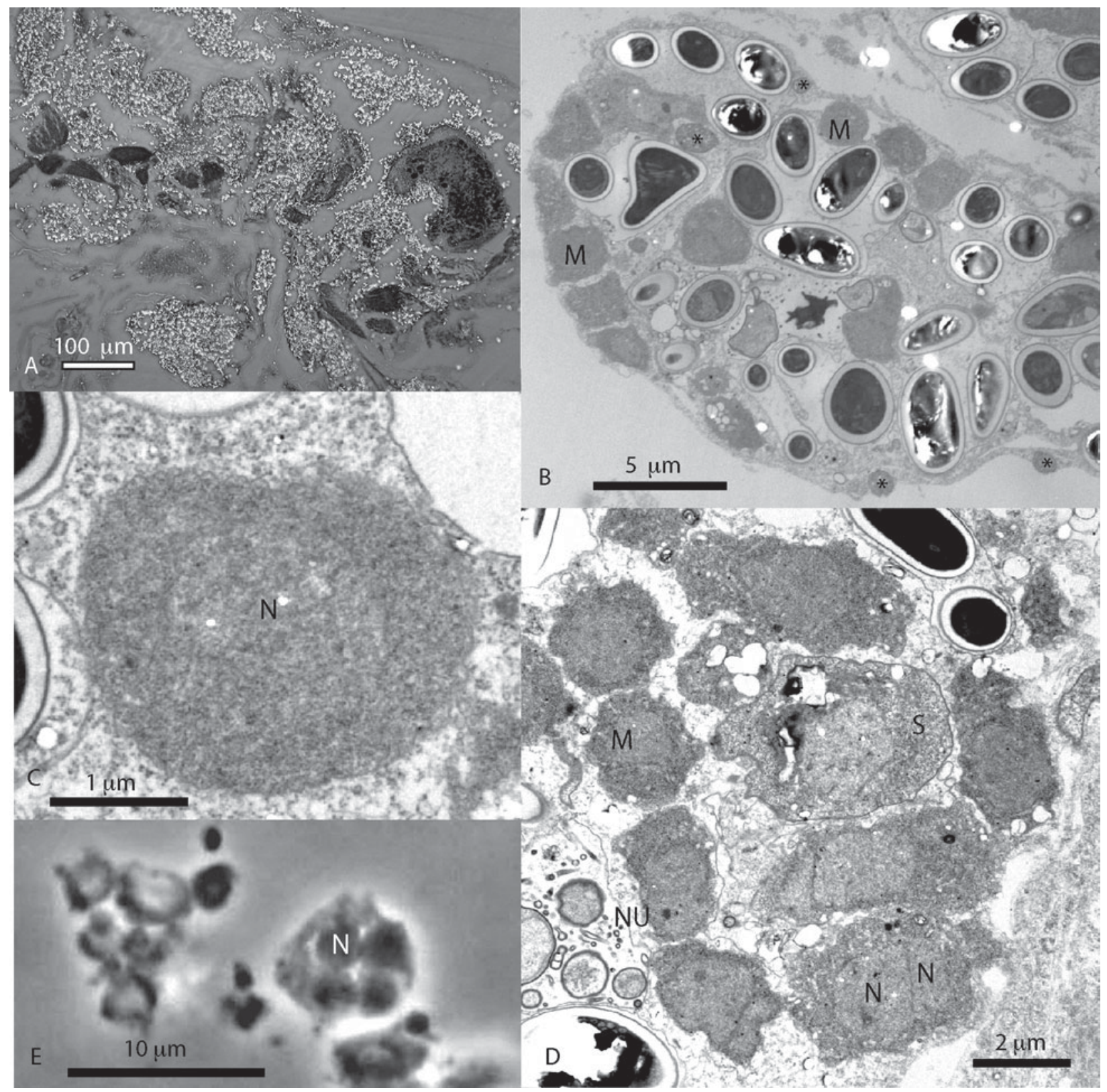

Fig. 1. Pathogenicity and early development of Hamiltosporidium tvaerminnensis sp. nov. (A) Longitudinal section showing microsporidian infection of fat tissue and hypodermis (haematoxylin staining, phase contrast). (B) Ultrathin section of infected fat tissue degraded into a syncytium; merogonial stages at the periphery; * indicates a host cell mitochondrion. (C) Merozoite. (D) Tetranucleate merogonial plasmodium (haematoxylin staining). (E) Chain-like arranged merozoites and sporonts. $\mathrm{M}$, merogonial stages; $\mathrm{N}$, nucleus; NU, nucleolus; $\mathrm{S}$, sporont.

shed from the surface in a blister-like fashion (Fig. 2A), but with progressive development they united to form a continuous rounded sac around the undivided sporont (Fig. 2B). Around later, fingerlike dividing stages, the vesicle followed the outline of the lobes fairly closely (Fig. 7B). The newly formed envelope was connected to the plasma membrane by tubules, $32-58 \mathrm{~nm}$ in diameter, with thinner walls than the envelope (Fig. 2C).

The thick sporont wall was initiated inside the vesicle primordial (Fig. 2C) -not in parallel arrays of dense material as is commonly seen in microsporidia -but appearing as wide fields at several places simultaneously on the surface (Fig. 2D). It developed rapidly to form a continuous and complete sporont wall (Fig. 2E). The primordial sporont wall measured approximately $32 \mathrm{~nm}$ in thickness. From the beginning it was composed of 2 layers: an electron-dense surface layer about $14 \mathrm{~nm}$ thick, separated from the plasma membrane by a layer of more lucent material (Fig. 2D). Concurrent with the development of the sporont wall, the nucleus divided to form a rounded-oval (Fig. 2E), and then ultimately a lobed plasmodium, yielding 8 uninucleate sporoblasts that matured to spores without further division (Fig. 2F). The most distinct finger-like plasmodia, which had narrow elongated lobes, produced elongated spores (Fig. 4B). 


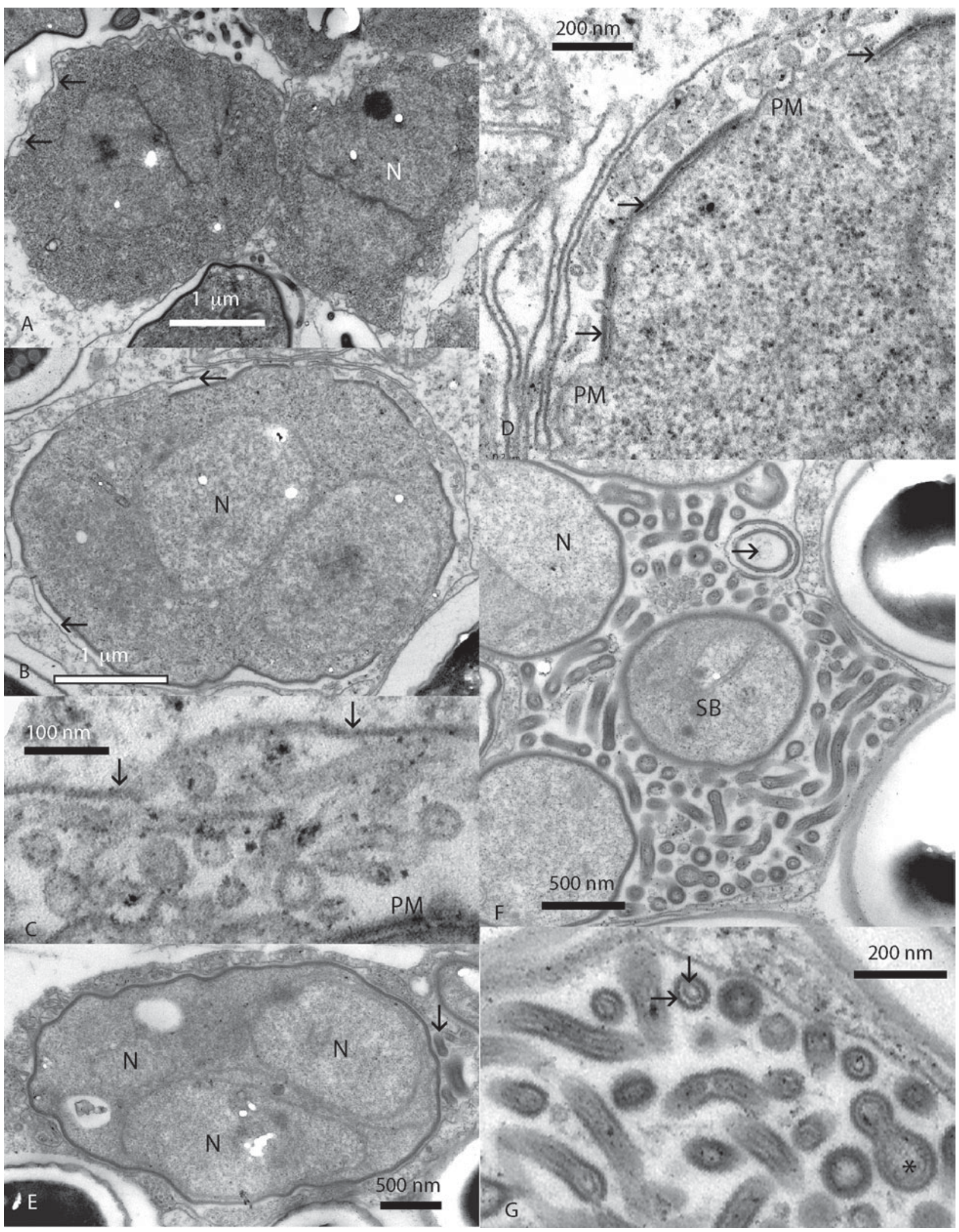

Fig. 2. Sporogony of Hamiltosporidium tvaerminnensis. (A) Sporonts with beginning production of a sporophorous vesicle (arrows). (B) Older binucleate sporont in an almost complete sporophorous vesicle (arrows). (C) First generation of tubules, arrows indicate the envelope of the sporophorus vesicle. (D) Early sporont with first generation of tubules; the sporont wall is initiated as wide areas of 2-layered material (arrows) outside the plasma membrane. (E) Older sporont with complete sporont wall and beginning production of tubules of the second generation (arrow). (F) Sporophorous vesicle with sporoblasts and tubules of the second generation; arrow points at a tubular widening. (G) Tubules of the second generation have 1 external and 1 internal component (arrows); asterisk indicates a widened region. N, nucleus; $\mathrm{PM}$, plasma membrane; SB, sporoblast. 


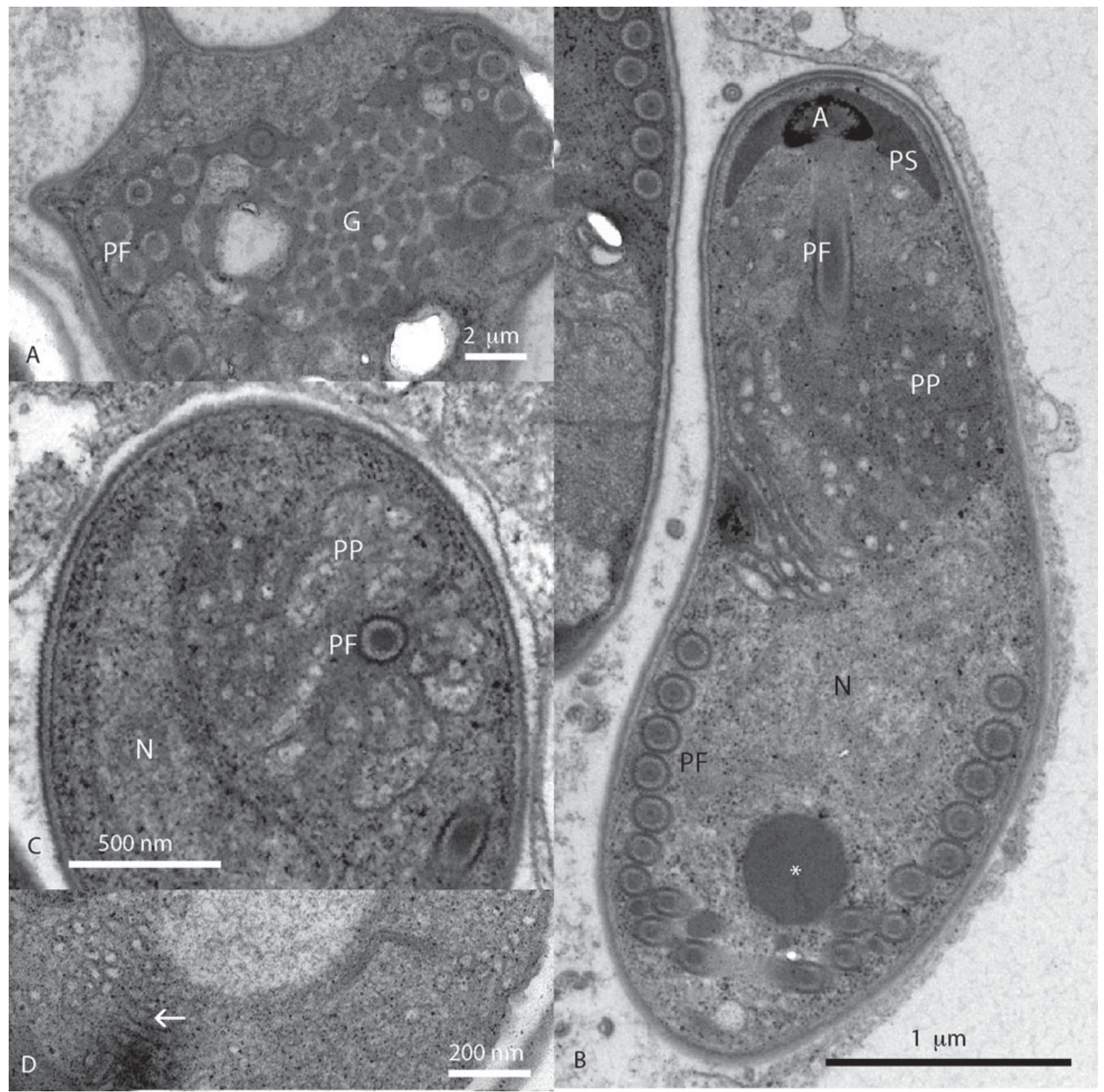

Fig. 3. Early aspects of sporal structures of Hamiltosporidium tvaerminnensis. (A) Sporoblast with developing polar filament. (B) Longitudinally sectioned immature spore; asterisk indicates a granular remainder of the Golgi vesicles. (C) Transversely sectioned immature spore showing petal-like developing polaroplast lamellae. (D) Detail of developing polaroplast lamellae showing internal tubular primordia (arrow). A, anchoring disc; G, Golgi vesicles; N, nucleus; $\mathrm{PF}$, polar filament; PP, polaroplast; PS, polar sac.

When the sporoblasts were individualized, a second generation of tubules with more electrondense walls appeared (Fig. 2F). These tubules filled the episporontal space like a mesh, and at least some of them appeared to be continuous from the sporoblast wall to the envelope of the sporophorous vesicle (Fig. 2F). This second generation of tubules had a double structure with a thin-walled tubulus inside a slightly thicker wall (Fig. 2G). Internal tubules measured about $30 \mathrm{~nm}$ in width, external tubules about $80 \mathrm{~nm}$. Characteristically the tubules swelled up to $0 \cdot 5 \mu \mathrm{m}$ wide at parts (Fig. $2 \mathrm{~F}-\mathrm{G}$ ).

Sporal organelles developed in the sporoblast and immature spore in the typical manner for microsporidia. The polar filament began in the posterior of the sporoblast from a spongious Golgi apparatus (Fig. 3A). The filament precursors formed in peripheral areas of electron-dense material, and the filament extended in front of the sporoblast as it grew. The membraneous surface layer of the filament grew from the surface membrane of the Golgi apparatus as the filament extended (Fig. 3A). The Golgi apparatus remained in immature and mature spores as 1 or more electron-dense membrane-lined posterior granules (Fig. 3B).

The polaroplast began in a petal-like manner as perpendicular lamellar folds from the surface of the polar filament (Fig. 3C). The membrane that 


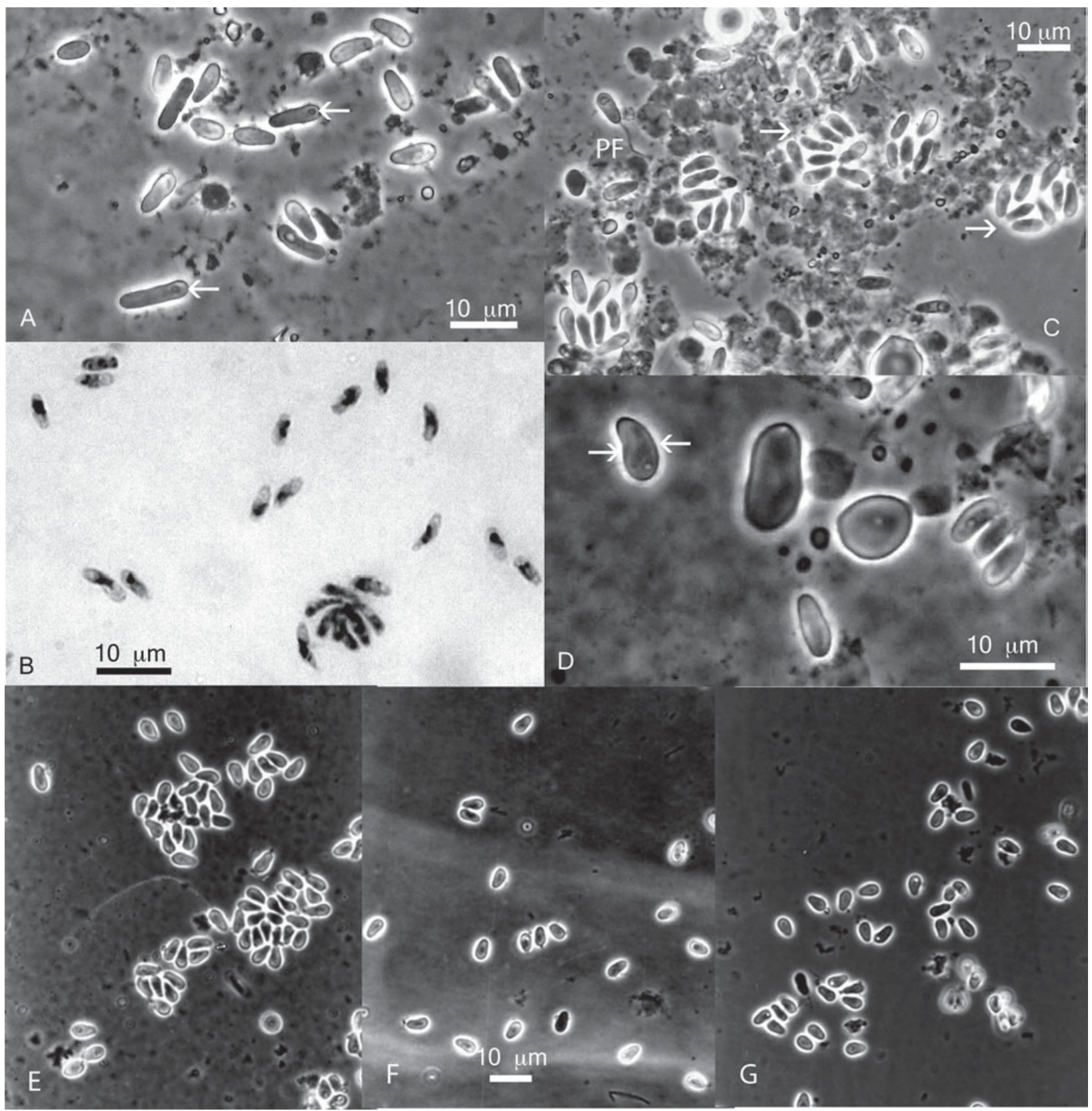

Fig. 4. Light microscopic aspect of Hamiltosporidium tvaerminnensis. (A) Unfixed pyriform and elongated spores; arrows point at vacuolar regions with a granular remainder of the Golgi vesicles. (B) Haematoxylin staining of mature spores and a flabelliform sporogonial plasmodium. (C) Unfixed smear showing octosporous groups of spores (arrows) and 1 ejected polar filament (PF). (D) Unfixed normal pyriform spores, with concave and convex sides (arrows), and macrospores. (E, F, G) The pyriform spores from F. magnivora from England (E), Belgium (F) and Moscow, Russia (G).

delimited the compartments of the polaroplast was continuous with the surface membrane of the polar filament, as found in all microsporidian spores (Vávra and Larsson, 1999). Sections parallel with the surface of the newly formed lamellae revealed an internal system of tubular priordial lamellae (Fig. 3D).

\section{The mature spores}

Mature spores were strikingly polymorphic (Fig. 4A, B), though pyriform spores with blunt ends dominated. These were slightly bent with 1 concave and 1 convex side. In unfixed spores, the posterior vacuole and a spherical body-remainders of the Golgi apparatus-were visible close to the posterior pole (Fig. 4A). Fresh pyriform spores measured 4.9$5 \cdot 6 \times 2 \cdot 2-2 \cdot 3 \mu \mathrm{m}$ (Vizoso et al. 2005). A second spore type was elongated and rod-like with blunt ends and a wider posterior end (Fig. 4A). These were straight or lightly curved, and also exhibited vacuole and spherical granules. This spore type measured $6 \cdot 8-$ $12 \cdot 0 \times 1 \cdot 6-2 \cdot 1 \mu \mathrm{m}$ (Vizoso et al. 2005). Both pyriform 


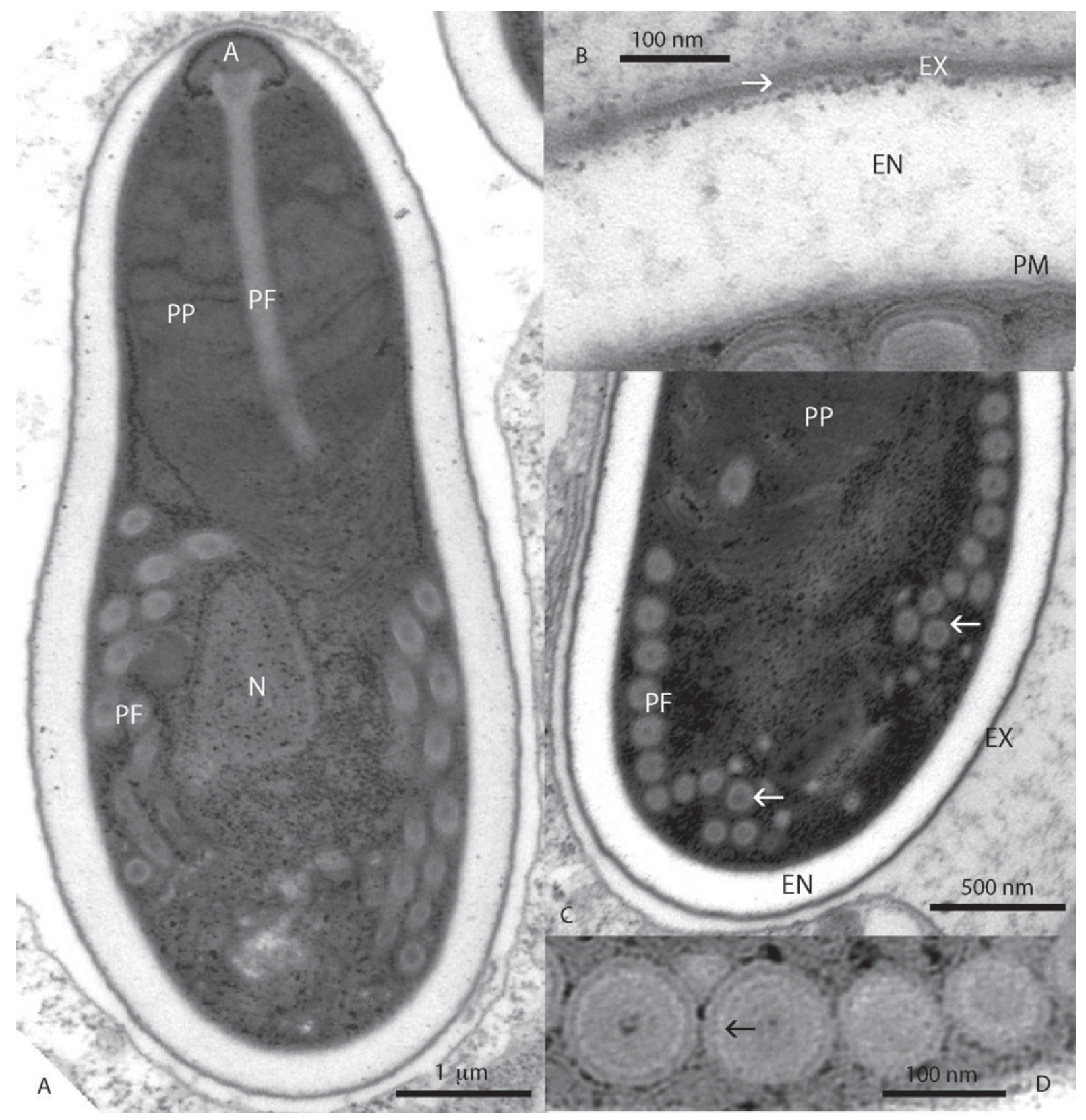

Fig. 5. The mature spore of Hamiltosporidium tvaerminnensis. (A) Longitudinal section. (B) Detail of the spore wall showing the layering of the exospore (arrow). (C) Longitudinally sectioned posterior region showing the coiling of the polar filament; arrows point at the most posterior wide coil. (D) Transversely sectioned polar filament; arrow points at the fibril-like layer. A, anchoring disc; EN, endospore; EX, exospore; N, nucleus; PF, polar filament; PM, plasma membrane; PP, polaroplast; R, ribosomes.

and rod-shaped macrospores occurred frequently (Fig. 4D). In cases of advanced infection, host cells and sporophorous vesicles were more likely to break in situ, and care had to be taken not to destroy the vesicles during squashing (Fig. 4C).

The pyriform spores and most of the elongated spores exhibited an identical ultrastructure. The spore wall was rather thick, measuring 180-260 nm (Fig. 5A) except at its most anterior section where, above the anchoring apparatus, the thickness was reduced to at least $65 \mathrm{~nm}$. The spore wall had the usual 3 components: From inside outwards, a thick (about $9 \mathrm{~nm}$ ) plasma membrane, a lucent endospore, and a symmetrically layered $40-45 \mathrm{~nm}$ thick exospore (Fig. 5B). The variation in thickness was caused by variable development of the endospore (Fig. 5A). The central layer of exospore was almost membranelike, electron-dense with darker borders (Fig. 5B). It was covered on both sides by less-dense layers of similar thickness. The less-dense layers were externally and internally delimited by thin strata of more electron-dense material, and at least the internal surface was fairly granular (Fig. 5B).

Squashing forced the polar filament to eject (Fig. 4C). In its unejected state, it was attached to a curved anchoring disc at the anterior pole of the spore 
(Fig. 5A). The disc measured $354 \mathrm{~nm}$ in diameter at its widest part. The straight part of the filament proceeded backwards for about one third of the spore length before turning sideways and ending in a coil that, at is outermost point, touched the posterior end of the spore (Fig. 5A, C). The filament usually formed 12-13 coils with slightly different diameters and arrangements (Fig. 5A, C). The straight part of the filament and the foremost 5-7 coils measured $122-148 \mathrm{~nm}$ in width, the posterior 7-6 coils measured 84-110 $\mathrm{nm}$ in diameter. The wider coils formed a single row, with the last wide coil often dislocated to the rear so that the final part of the filament formed an irregular group of slightly more narrow coils in front of the final wide coil (Fig. 5C). The transversely sectioned polar filament exhibited a distinct layered substructure: a central dark area, a moderately dense zone with concentric layering, a stratum appearing as transversely sectioned lucent fibrils, an external zone with dense and moderately dense layering, and a membrane cover (which appeared electron dense in some preparations) (Fig. 5D).

The mature polaroplast had an unusual construction with 3 distinct lamellar regions (Fig. 5A). The anterior region was short with up to approximately 10 closely arranged lamellar folds (periodicity from dark centre to dark centre about $15 \mathrm{~nm}$ ) (Fig. 6A). The median section, measuring about one third of the spore length, had distinctly wide, angular or rounded compartments at least $280 \mathrm{~nm}$ wide (Fig. 6A). These compartments almost touched the spore wall. The final region also had closely packed lamellae (periodicity from dark centre to dark centre about $25 \mathrm{~nm}$ ). It tapered towards the posterior end, terminating at the most anterior filament coil (Figs. 5A and 6B).

The nucleus in the posterior half of the spore was slender (Fig. 5A), measuring $1.45 \mu \mathrm{m}$ at its widest sections. At the posterior pole, in a slightly oblique position, was a vacuole and occasionally a posterior granule up to $320 \mathrm{~nm}$ wide- the membrane-like remainders of the Golgi apparatus. The membrane surrounding the polar filament, forming the lamellae of the polaroplast and delimiting the posterior granule and vacuole, belonged to the same system and was slightly narrower (about $6 \mathrm{~nm}$ wide) than the plasma membrane. The cytoplasm was fairly dense with strands of polyribosomes around the polaroplast, nucleus and filament coils (Fig. 5A).

\section{Unusual and teratological development}

The species described here exhibited some developmental and cytological characteristics unusual to microsporidia. For example, sporophororous vesicles sometimes contained sporoblasts of 2 ages (Fig. 7A). In addition, sporoblasts with developing extrusion apparatuses, and even mature spores, were still connected (Fig. 7B). Macrospores of both shapes

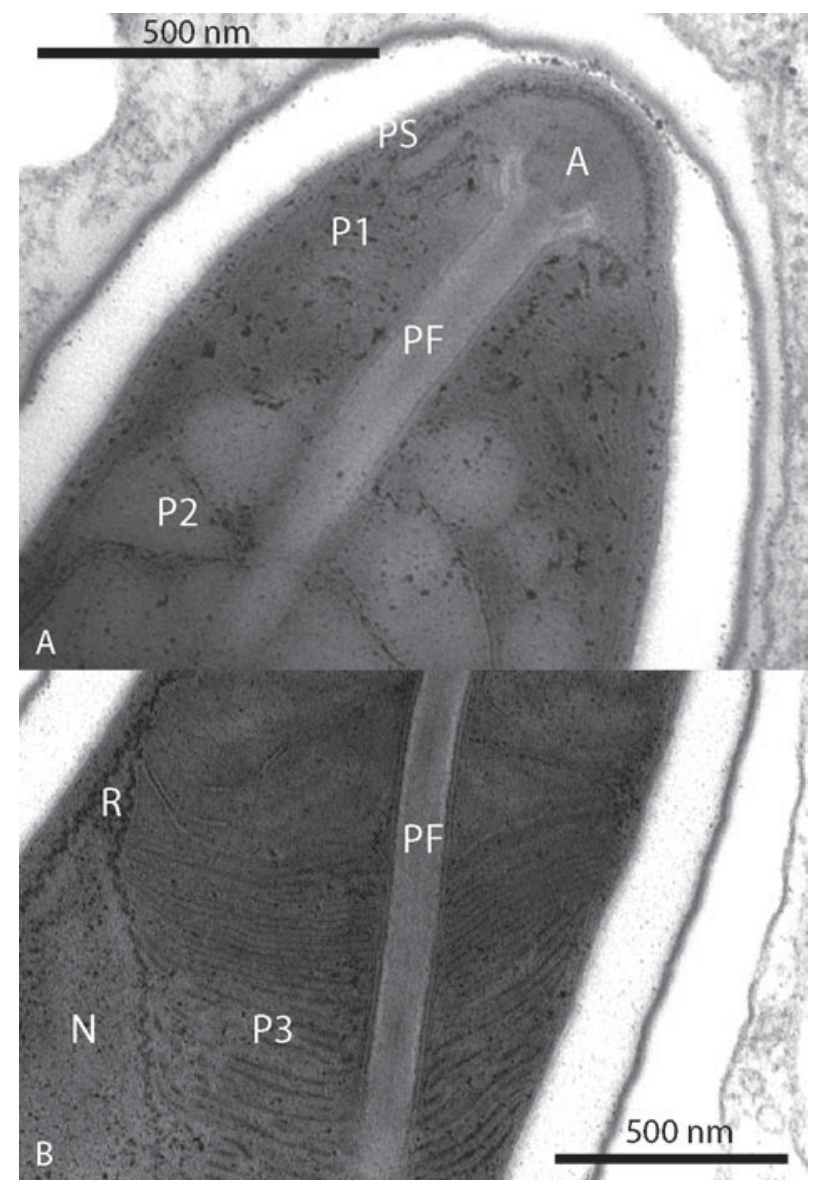

Fig. 6. The mature polaroplast of Hamiltosporidium tvaerminnensis. (A) Anterior part with lamellar (P1) and almost globular (P2) chambers. (B) Posterior part (P3) with lamellae. A, anchoring disc; N, nucleus; $\mathrm{PF}$, polar filament; PS, polar sac; R, ribosomes.

(pyriform and rod-shaped) were diplokaryotic (Fig. 7C), with more filament coils—at least up to 18 . Apart from that, their sporal cytology was identical to other spores. Polyribosomes had an unusual construction: transverse sections exhibited 9 ribosomes arranged in a circle about $70 \mathrm{~nm}$ wide (Fig. 7D).

\section{Comparison to Octosporea bayeri}

In earlier papers, this microsporidium has been referred to as Octosporea bayeri Jírovec, 1936 (Green, 1957, 1974; Ebert et al. 2001; Vizoso et al. 2005). O. bayeri, a parasite of the adipose tissue, was isolated from D. magna hosts living in Moravia (Jírovec, 1936). It was described briefly, as was typical for the time, and illustrated with a few line drawings. $O$. bayeri produces fairly large spores that are more or less rod-like, straight or lightly curved with blunt ends. The posterior vacuole is prominent in living spores. Feulgen techniques have revealed the spores to be binucleated, and Giemsa staining revealed a metachromatic posterior granulum. Nothing is known about the species' reproductive process. O. bayeri shares some characteristics with the novel 


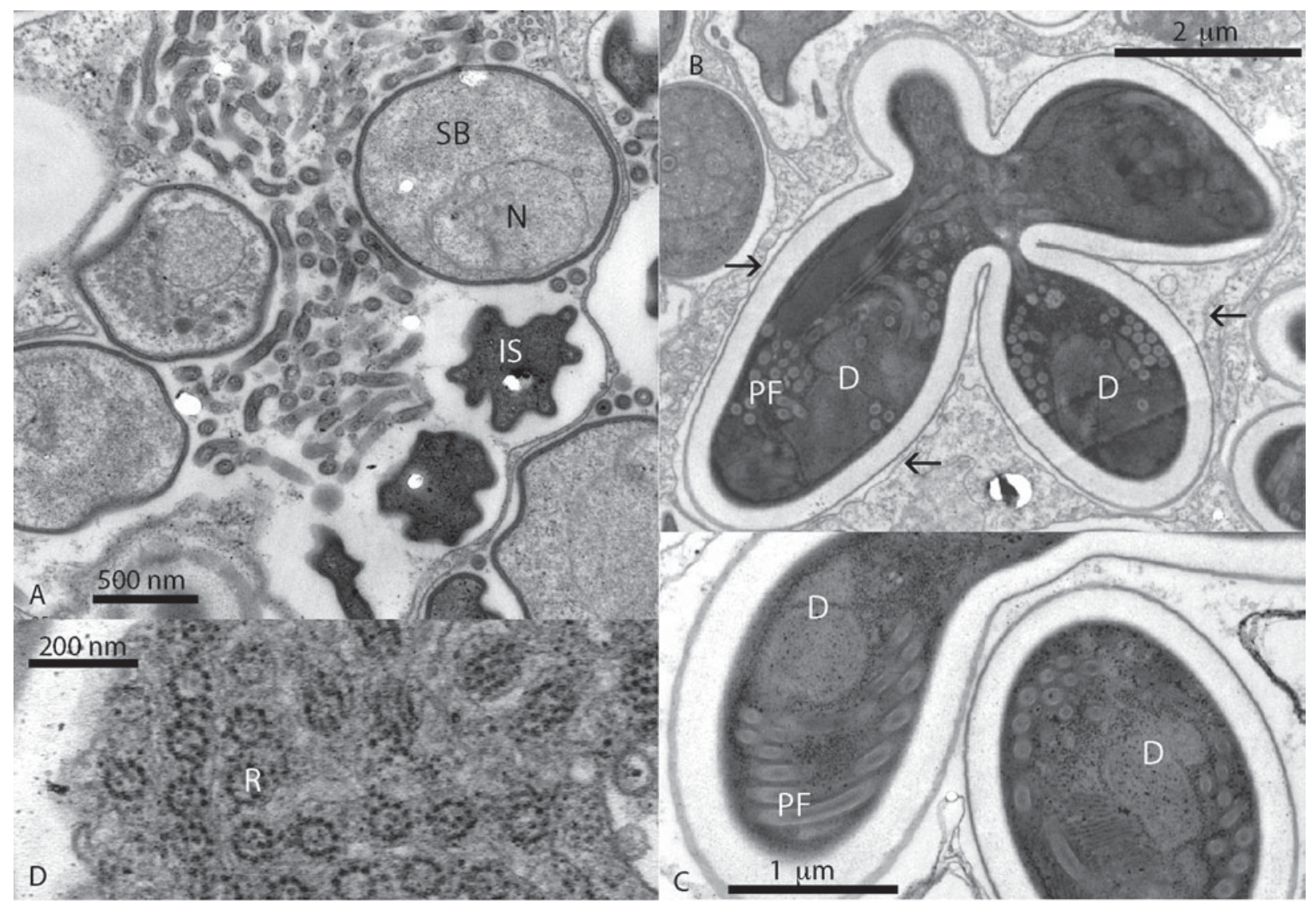

Fig. 7. Untypical microsporidian features of Hamiltosporidium tvaerminnensis. (A) Sporophorus vesicle with both sporoblasts and immature spores. (B-C) Flabelliform sporogonial plasmodia with still connected diplokaryotic mature macrospores; arrows point at sporophorous vesicle following the lobes of the plasmodium. (D) Transversely sectioned polyribosomes showing circles of 9 ribosomes (R). D, diplokaryotic mature macrospores; IS, immature spores; PF, polar filament; N, nucleus; SB, sporoblasts; SV, sporophorus vesicle.

species described in this paper: The elongated spores are also large and match Jírovec's drawings. The host and pathology are identical. At the most basic microscopic level, thus, there are no distinct differences between this species and O. bayeri.

Knowledge of the ultrastructure and study of Jírovec's type material, however, clarify that the microsporidium described here must be another species. The normal spores of $H$. tvaerminnensis are octosporous, in fragile sporophorous vesicles and not diplokaryotic. Although it is not possible to verify the diplokaryotic condition of $O$. bayeri from the type slides, neither pyriform spores nor octosporous groups are observable. Even if a fragile sporophorous vesicle easily breaks when making smears, spore groups might be revealed if several smears are studied, as some groups of spores and sporoblasts are likely to remain in positions where host tissue is present in the smears. There are 2 types of spores in these slides, but the large groups of smaller spores are correctly identified on the labels, by Jírovec's hand, as the gut parasite Pleistophora intestinalis (now transferred to the genus Glugoides) (Larsson et al. 1996).

Geographical distribution also suggests that the earlier identification as $O$. bayeri was incorrect. The species described here was only found in D. magna populations inhabiting rock pools on the Skerry islands of the Baltic coast of Sweden and Finland. Field sampling in other European countries (Russia, UK, Belgium, France, Switzerland, Germany) revealed no evidence of this species (D. Ebert, unpublished observations). Two sampling expeditions to the Nesyt pond in Moravia, Czech Republic, the type locality of $O$. bayeri, did not reveal any microsporidian parasite of the adipose tissue of D. magna (D. Ebert, unpublished observations). Furthermore, the ecology of the large permanent Nesyt pond differs markedly from that of the small intermittent coastal rock pools on the Skerry islands.

Jírovec (1936) justified placing this new species in the genus Octosporea based on the shape of its spores. The type species, O. muscaedomesticae Flu, 1911, was studied at the ultrastructural level, and was proven to be diplokaryotic in all developmental stages (Ormières et al. 1976). Consequently. the species described here cannot be classified in the genus Octosporea.

\section{Molecular evolutionary analyses}

The species described here is similar to F. magnivora and, according to the present and previous analyses, 


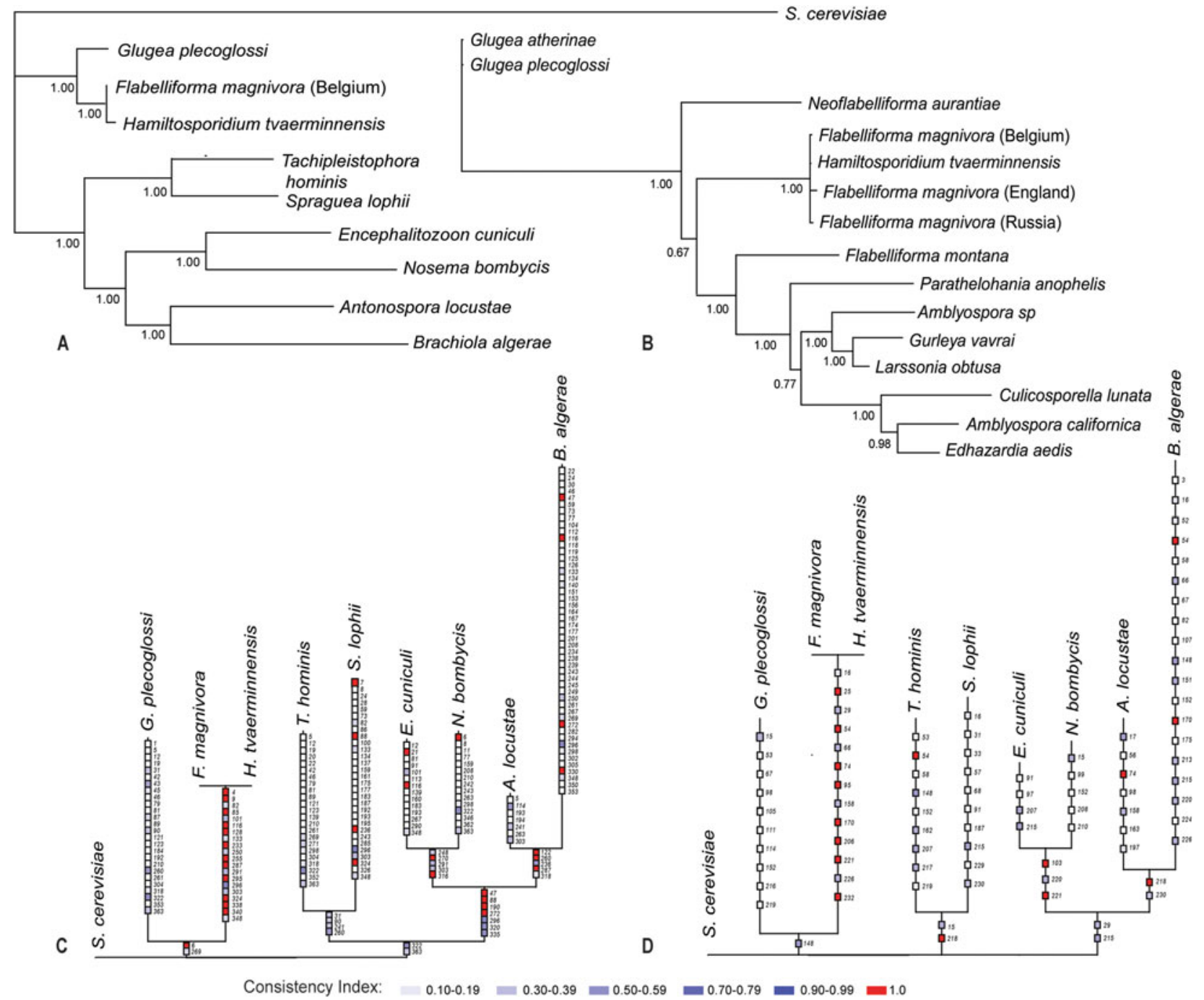

Fig. 8. Phylogeny inferences. (A) Bayesian phylogeny based on a mixed dataset containing 369 amino acids of alpha tubulins, 233 amino acids of beta tubulins and 1464 nucleotides of SSU rDNA. Numbers indicate the posterior probability of each internal node. (B) Bayesian phylogeny based on 1082 nucleotides of SSU rDNA. (C) Unambiguous amino acid replacements of alpha tubulins plotted on the tree shown in (A). (D) Unambiguous amino acid replacements of beta tubulins plotted on the tree shown in (A).

they are more related to the genus Glugea than to other well-known microsporidians, such as Antonospora and Encephalitozoon (Fig. 8A; Corradi et al. 2009; Refardt et al. 2002). The tree is characterized by very long tip branches, except for the cluster with our target species. Although posterior probabilities indicate a good statistical confidence for all clades, it is possible to verify that the internal branches are supported by a reduced number of characters (Fig. 8C, D). This contrasts with the new species/ $F$. magnivora cluster, which shows a long internal branch and very short tip branches. No amino acid differences were found in the alpha- and betatubulins of either species (Fig. $8 \mathrm{C}, \mathrm{D}$ ), but $1.3 \%$ of the nucleotides differ in their SSU rDNA sequences.

Hamiltosporidium tvaerminnensis shares cytological characteristics with Flabelliforma magnivora, $F$. montana, and with another crustacean parasite, Agmasoma penaei (Hazard and Oldacre, 1975). To clarify their phylogenetic position in a group of closely related microsporidians, we used only the SSU rDNA sequences in a similar phylogenetic analysis (Fig. 8B), in which Glugea was considered as outgroup, based on a previously published SSU phylogeny (Refardt et al. 2002). The tree shows that $H$. tvaerminnensis and F. magnivora group neither with $F$. montana, nor with the recently described Neoflabelliforma aurantiae. Agmasoma penaei is not presented in the tree, because its partial SSU rDNA sequence is much shorter than the remaining sequences.

\section{DISCUSSION}

\section{Phenetic relationships}

The species described here shares cytological characteristics with 2 Flabelliforma species: the type species 
F. montana, a parasite of Diptera (sandflies) (Canning et al. 1991, 2001), and F. magnivora, also a parasite of Daphnia magna (Larsson et al. 1998), and with Agmasoma penaei, a parasite of shrimps (Hazard and Oldacre, 1975; Clotilde-Ba and Toguebaye, 1994). The uninucleate development, the finger-like division, the 2-layered tubules of the episporontal space, and the more or less pyriform spores with 1 convex and 1 concave surface are all characteristics shared by H. tvaerminnensis and the 2 Flabelliforma species.

The early developmental stages of the species described here appear identical to those of $F$. magnivora (Larsson et al. 1998). The sporont walls are initiated identically over wide areas in both species (Larsson et al. 1998) as it also is in F. montana (Canning et al. 2001: Fig. 12). However, the fine structure of the primordia of the sporont wall (exospore) differs in $F$. montana. In $F$. magnivora and the species described here, the sporont wall originates directly as a layered structure, whereas in $F$. montana the primordium originates as an electron-dense material with cavities, and the layering is achieved during the maturation of the sporont (Canning et al. 2001: Fig. 8). In both $F$. magnivora and the species described in this paper, the exospores of mature spores are identically constructed, but differ in thickness. F. montana has a similarly layered exospore with unit membrane-like external and internal delimitations (Canning et al. 2001: Fig. 25).

The present species and the 2 Flabelliforma species produce 2 generations of tubules in the episporontal space: first, thin-walled tubules, and then more thickwalled double-layered tubules. In the species described here, tubules disappear almost completely when the spores mature, leaving only granular remnants. In $F$. magnivora and $F$. montana, however, some tubules remain around mature spores (Larsson et al. 1998: Fig. 16; Canning et al. 2001: Fig. 21). In $F$. montana and the present species, second-generation tubules widen in a characteristic way.

Spores of $F$. magnivora and $F$. montana are slightly broader than spores of the present species. $F$. magnivora mature spores have a greater number of filament coils than the species described here, and they are arranged as 2 irregular rows of coils (Larsson et al. 1998: Figs. 14, 15). F. montana mature spores have a short filament with a few identical coils (Canning et al. 2001: Fig. 24). F. magnivora mature spores also show no size difference between anterior and posterior coils, unlike the present species, although immature spores exhibit slightly wider anterior coils (Larsson et al. 1998: Fig. 14). The internal organization of the filament is identical in the present species and $F$. magnivora, and probably also in F. montana. The polaroplast of F. magnivora, and $F$. montana is the most common type for microsporidia, with 2 lamellar regions: tightly arranged anterior lamellae, and wider posterior lamellae (Larsson et al.
1998: Fig. 20). This differs from the species described here. In F. magnivora, and the species of this paper, some spores remain connected until full maturation (Larsson et al. 1998: Fig. 22). These 2 species also share circularly arranged polyribosomes (Larsson et al. 1998: Fig. 27).

The present species shares many characteristics with both Flabelliforma species and is clearly more closely related to $F$. magnivora; however, even here there are distinct cytological differences between the two species, beyond structure. The spores of $F$. magnivora are smaller and more uniform; they are formed in a variable number; the polar filament is isofilar in mature spores and is coiled in double layers. The polaroplast does not contain an intermediate region with wider lamellae. The tubules of the episporontal space are more persistent, have thicker walls and no characteristic widened sections. A further, very distinct difference between $F$. magnivora and the species described here is the presence of the elongated spore type in the new species, which has never been found in any isolate of $F$. magnivora, despite an intensive search in infected hosts at all stages of infection and from several localities (Larsson et al. 1998, D. Ebert, personal observations). Taken together, these differences indicate that the species described here and F. magnivora are different species, even if they clearly belong to the same genus.

Agmasoma penaei shares several characteristics with H. tvaerminnensis: it produces octosporoblastic pyriform spores; the sporophorous vesicles have similar 2-layered tubules, and the exospores are obviously identical (Hazard and Oldacre, 1975; Clotilde-Ba and Toguebaye, 1994). However, merogonial stages and sporonts are diplokaryotic; sporoblasts are not released by budding; the polaroplast has 2 lamellar regions; and the size differences between anterior and posterior polar filament coils are so great that the filament clearly must be characterized as anisofilar. These differences indicate that the species described here is clearly not an Agmasoma species, a conclusion that is also supported by molecular data (not shown).

Recently, Morris and Freeman (2010) suggested removing $F$. magnivora from the genus Flabelliforma, because of its strong sequence divergence from $F$. montana and to place it in the new genus Neoflabelliforma. Following their reasoning we would need to place the new species in this genus as well. However, we disagree with the placement of F. magnivora in the genus Neoflabelliforma. Fixed spores of Neoflabelliforma aurantiae were described as ovoid to lageniform, and the single micrograph shows spores that are similar, but not identical to $F$. magnivora. The anterior pole of the spores of $N$. aurantiae is clearly more blunt and the spores are symmetrical. The spores of $F$. magnivora have a more pointed anterior pole and one of the sides is slightly convex. 
There are some obvious cytological differences between $N$. aurantiae and $F$. magnivora. The exospore of $N$. aurantiae originates as parallel strands of electron-dense material (Fig. $4 \mathrm{~A}$ in Morris and Freeman (2010)), not as wide areas as in $F$. magnivora. Both species produce tubular exospore projections during the sporogony. Obviously $N$. aurantiae produces only 1 generation of tubules, while $F$. magnivora, like $H$. tvaerminnensis, produces 2 generations. The last generation of tubules of $F$. magnivora is distinctly double-layered, different from the tubules of $N$. aurantiae. The characteristics of the spore of $N$. aurantiae are very general, but some obvious differences to $F$. magnivora are apparent. The exospore of $N$. aurantiae forms external projections and the polaroplast is described as uniform, not divided into 2 or more regions.

\section{Phylogenetic relationships and genetic divergence}

The close relationship of $F$. magnivora and the new species here described is supported by their reduced molecular divergence. A phylogenetic tree of all microsporidian species with SSU rRNA, alphatubulin and beta-tubulin genes available in GenBank supports the sister species status for $F$. magnivora and the new species, justifying their placement in 1 genus. Their alpha and beta tubulin amino acid sequences are identical, while several unambiguous replacements occur along the remaining branches of the tree. Tubulin genes have not been obtained for F. montana, $A$. penai and the recently described species $N$. aurantiae. Nevertheless, the phylogeny inferred from SSU sequences only further indicates that the species described here is the closest relative of $F$. magnivora. It must be emphasized that the power of DNA sequences for identifying species is limited when species pairs have very recent origins (Tautz et al. 2003). The buildup of sequence differences that can serve as unequivocal diagnostic characters, depends on the mutation and fixation rates, which, for nuclear neutral sites, amount $0 \cdot 1-0 \cdot 2 \%$ per million years (combined estimates). Unfortunately, the genome of $H$. tvaerminnensis seems to be poor in repetitive sequences, which have a higher mutation rate, but we are attempting to isolate microsatellites, which could be used as population genetic markers for both the species described here and F. magnivora. Our preliminary results on 6 microsatellite loci show a complete lack of polymorphism in H.tvaerminnensis, but not for 2 loci in $F$. magnivora, with no shared alleles between the two species (data not shown). Together with the cytological and ecological data, our molecular studies fit with a scenario of very recent speciation, possibly after the last glaciation, when the Scandinavian ice sheet started to melt down (about 10000 years BP).

An alternative explanation for our findings is that H. tvaerminnensis simply represents a subspecies or an ecotype of F. magnivora. We do not think that this is the case, because the morphologic and ecological characters that distinguish the two species are not polymorphic across Europe in F. magnivora, and there are no intermediate states. Moreover, our molecular data suggest that the species described here is completely asexual (data not shown). Asexual reproduction might have led to reproductive isolation, and, consequently, to specialization and speciation.

\section{CONCLUSION}

We propose placing the species described here in a new genus called Hamiltosporidium and name it $H$. tvaerminnensis. Based on its close relationship with $F$. magnivora we further propose transferring $F$. magnivora to Hamiltosporidium. Molecular differences between $F$. montana and $F$. magnivora justify their placement into different genera. Our data are consistent with the hypothesis that $H$.tvaerminnensis recently split from $F$. magnivora, forming a new species. Further investigations into the similarities and differences of these two species may allow a deeper understanding of the process that led to this speciation event.

\section{Description}

\section{Hamiltosporidium gen. nov.}

Merogonial and sporogonial stages with isolated nuclei. Sporogony by more or less flabelliform budding in a sporophorous vesicle produced at the beginning of sporogony, the number of sporoblasts variable, about 8 . Sporont wall initiated as a 2-layered stratum. Episporontal space with 2 generations of tubules: first generation thin-walled, second generation 2-layered, formed in the sporoblastogenesis. Tubules reduced when spores mature. Spores pyriform and elongated with more or less isofilar polar filament and a polaroplast with 2-3 basically lamellar regions.

Derivation of name: in honour of William Donald Hamilton, FRS (1 August 1936-7 March 2000) for his contributions to the role of infectious diseases in the ecology and evolution of natural populations.

\section{Species 1: Hamiltosporidium tvaerminnensis sp. nov., type species}

Pre-sporal development: merogonial stages with isolated nuclei, merozoites formed by binary fission or cleaving of a plasmodium with a small number of nuclei. It is unknown if there is more than 1 merogonial cycle.

Sporogony: octosporoblastic. A sporogonial plasmodium with isolated nuclei yields 8 sporoblasts by budding or the sporont divides into 2 daughter cells each giving rise to a tetranucleate plasmodium. Elongated spores are generated by the most flabelliform plasmodia. 
Spores: polymorphic in shape and size. The majority of spores are pyriform, with 1 concave and 1 convex side. Posterior vacuole and refractive globule visible in living spores. Unfixed pyriform spores measure $4 \cdot 9-5 \cdot 6 \times 2 \cdot 2-2 \cdot 3 \mu \mathrm{m}$. Elongated, rod-shaped spores with blunt ends measure unfixed $6 \cdot 8-12 \cdot 0 \times 1 \cdot 6-2 \cdot 1 \mu \mathrm{m}$. The spore wall measures $160-$ $280 \mathrm{~nm}$, with a $40-45 \mathrm{~nm}$ wide 5-layered exospore. The polar filament is normally arranged in 12-13 coils. Anterior 5-7 coils, in one row of coils, are 122-148 nm wide, posterior 6-7 coils, in an irregular group of coils, measure $84-110 \mathrm{~nm}$ in diameter. Polaroplast with 3 regions: densely arranged lamellae, wide chamber-like lamellae, and posterior densely arranged lamellae. Nucleus, in sections up to $1.45 \mu \mathrm{m}$ in width, in the posterior half of the spore. Macrospores diplokaryotic with increased number of polar filament coils.

Sporophorous vesicle: a thin, fragile envelope is formed at the beginning of the sporogony. Thinwalled, $32-58 \mathrm{~nm}$ wide tubules are formed at the beginning of sporogony. When sporoblasts form, a second type of double-layered tubules (internal tubulus about $30 \mathrm{~nm}$ wide, external tubulus about $80 \mathrm{~nm}$ in diameter) appears, filling the episporontal space as a meshwork. These tubules characteristically have swollen areas. Tubules disappear during the maturation of the spores leaving a granular remainder.

Tissues involved: adipose tissue, hypodermis and ovaries.

Type host: Daphnia magna Straus, 1820 (Crustacea: Cladocera: Daphniidae).

Type locality: Rock pool on the Skerry island Ören $7 \cdot 5 \mathrm{~km}$ south-west of Tvärminne Zoological Station, Hanko, South-West Finland.

Types: Syntypes on slides No. 090512-A-(1-5). The sequences of the draft genome are available at http://www.ncbi.nlm.nih.gov/ (GenBank Accession code: ACSZ00000000.1).

Deposition of types: in the International Protozoan Type Slide Collection at Smithsonian Institution, Washington DC, USA.

Derivation of name: the species was first found at Tvärminne Zoological station in South-West Finland (Green, 1957).

\section{Species 2: Hamiltosporidium magnivora} (Larsson, Ebert, Mangin \& Vávra, 1998)

Synonym: Flabelliforma magnivora (Larsson et al. 1998)

Details on the cytology and type locality are given in Larsson et al. (1998).

\section{ACKNOWLEDGEMENTS}

The authors are greatly indebted to Rita Wallén at the Departement of Cell and Organism Biology, University of Lund, and to Jürgen Hottinger at Basel University. We thank Ellen Decaestecker and Mike Jansen for providing samples from Belgium.
FINANCIAL SUPPORT

The project was supported by the Swiss National Science Foundation (to K.H., D.E. and D.R.) and the Brazilian CNPq (process 201401/2007-0) (K.H.).

REFERENCES

Altermatt, F., Hottinger, J. W. and Ebert, D. (2007). Parasites promote host gene flow in a metapopulation. Evolutionary Ecology 21, 561-575.

Bieger, A. and Ebert, D. (2009). Expression of parasite virulence at different host population densities under natural conditions. Oecologia (Berlin) 160, 247-255.

Canning, E. U., Curry, A., Cheney, S. A., Lafranchi-Tristem, N. J., Ebert, D., Refardt, D., Killick-Kendrick, M. and Killick-Kendrick, R. (2001). Flabelliforma montana (Phylum Microsporidia) from Phlebotomus ariasi (Diptera, Psychodidae): ultrastructural observations and phylogenetic relationships. European Fournal of Protistology 37, 207-221.

Canning, E. U., Killick-Kendrick, R. and Killick-Kendrick, M. (1991). A new microsporidian parasite Flabelliforma montana n.g., n.sp. infecting Phlebotomus ariasi (Diptera, Psychodidae) in France. Fournal of Invertebrate Pathology 57, 71-81.

Clotilde-Ba, F. L. and Toguebaye, B. S. (1994). Ultrastructure and development of Agmasoma penaei (Microspora, Thelohaniidae) found in Penaeus notialis (Crustacea, Decapoda,Penaeidae) from Senegal. European Fournal of Protistology 30, 347-353.

Corradi, N., Haag, K. L., Pombert, J. F., Ebert, D. and Keeling, P. J. (2009). Draft genome sequence of the Daphnia pathogen Octosporea bayeri: insights into the gene content of a large microsporidian genome and a model for host-parasite interactions. Genome Biology 10, R106.

Decaestecker, E., Declerck, S., De Meester, L. and Ebert, D. (2005). Ecological implications of parasites in natural Daphnia populations. Oecologia (Berlin) 144, 382-390.

Ebert, D. (2005). Ecology, Epidemiology and Evolution of Parasitism in Daphnia, http://www.ncbi.nlm.nih.gov/ entrez/query.fcgi?db=Books, Bethesda (MD): National Library of Medicine (US), National Center for Biotechnology Information.

Ebert, D. (2008). Host-parasite coevolution: insights from the Daphnia-parasite model system. Current Opinion in Microbiology 11, 290-301.

Ebert, D., Hottinger, J. W. and Pajunen, V. I. (2001). Temporal and spatial dynamics of parasites in a Daphnia metapopulation: which factors explain parasite richness? Ecology 82, 3417-3434.

Ebert, D., Lipsitch, M. and Mangin, K. L. (2000). The effect of parasites on host population density and extinction: experimental epidemiology with Daphnia and six microparasites. American Naturalist 156, 459-477.

Green, J. (1957). Parasites and epibionts of Cladocera in rock pools of Tvärminne archipelago. Archivum Societatis Zoologicae Botanicae Fennicae 'Vanamo' 12, 5-12. 
Green, J. (1974). Parasites and epibionts of Cladocera. Transactions of the Zoological Society of London 32, 417-515.

Hazard, E. I. and Oldacre, S. W. (1975). Revision of Microsporida (Protozoa) close to Thelohania, with descriptions of one new family, eight new genera, and thirteen new species. U.S. Department of Agriculture Technical Bulletin 1530, 1-104.

Hostounský, Z. and Žižka, Z. (1979). A modification of the "agar cushion method" for observation and photographic recording microsporidian spores. Fournal of Protozoology 26, 41A-42A.

James, T. Y., Kauff, F., Schoch, C. L., Matheny, P. B., Hofstetter, V., Cox, C. J., Celio, G., Gueidan, C., Fraker, E., Miadlikowska, J., Lumbsch, H. T., Rauhut, A., Reeb, V., Arnold, A. E., Amtoft, A., Stajich, J. E., Hosaka, K., Sung, G.-H., Johnson, D., O'Rourke, B., Crockett, M., Binder, M., Curtis, J. M., Slot, J. C., Wang, Z., Wilson, A. W., Schüssler, A., Longcore, J. E., O'Donnell, K., MozleyStandridge, S., Porter, D., Letcher, P. M., Powell, M. J., Taylor, J. W., White, M. M., Griffith, G. W., Davies, D. R., Humber, R. A., Morton, J. B., Sugiyama, J., Rossman, A. Y., Rogers, J. D., Pfister, D. H., Hewitt, D., Hansen, K., Hambleton, S., Shoemaker, R. A., Kohlmeyer, J., Volkmann-Kohlmeyer, B., Spotts, R. A., Serdani, M., Crous, P. W., Hughes, K. W., Matsuura, K., Langer, E., Langer, G., Untereiner, W. A., Lücking, R., Büdel, B., Geiser, D. M., Aptroot, A., Diederich, P., Schmitt, I., Schultz, M., Yahr, R., Hibbett, D. S., Lutzoni, F., McLaughlin, D. J., Spatafora, J. W. and Vilgalys, R. (2006). Reconstructing the early evolution of Fungi using a six-gene phylogeny. Nature, London 443, 818-822. doi: 10.1038/nature05110

Jírovec, O. (1936). Über einige in Daphnia magna parasitierende Mikrosporidien. Zoologischer Anzeiger 116, 136-142.

Larsson, J. I. R. (1988). Identification of Microsporidia genera (Protozoa, Microspora) - a guide with comments on the taxonomy. Archiv für Protistenkunde 136, 1-37.

Larsson, J. I. R. (1999). Identification of Microsporidia. Acta Protozoologica 38, 161-197.

Larsson, J. I. R., Ebert, D., Mangin, K. L. and Vavra, J. (1998). Ultrastructural study and description of Flabelliforma magnivora sp n (Microspora :

Duboscqiidae), a microsporidian parasite of Daphnia magna (Crustacea : Cladocera : Daphniidae). Acta Protozoologica 37, 41-52.

Larsson, J. I. R., Ebert, D., Vavra, J. and Voronin, V. N. (1996). Redescription of Pleistophora intestinalis Chatton, 1907, a microsporidian parasite of Daphnia magna and Daphnia pulex, with establishment of the genus Glugoides (Microspora, Glugeidae). European Fournal of Protistology 32, 251-261.

Lass, S. and Ebert, D. (2006). Apparent seasonality of parasite dynamics: analysis of cyclic prevalence patterns. Proceedings of the Royal Society of London, B 273, 199-206.

Lee, S. C., Corradi, N., Byrnes III, E. J., Torres-Martinez, S., Dietrich, F. S., Keeling, P. J. and Heitman, J. (2008). Microsporidia evolved from ancestral sexual fungi. Current Biology 18, 1-5.

Mangin, K. L., Lipsitch, M. and Ebert, D. (1995).

Virulence and transmission modes of two microsporidia in Daphnia magna. Parasitology 111, 133-142.

Morris, D. J. and Freeman, M. A. (2010). Hyperparasitism has wide-ranging implications for studies on the invertebrate phase of myxosporean (Myxozoa) life cycles. International Fournal for Parasitology 40, 357-369.

Ormières, R., Baudoin, J., Brugerolle, G. and Pralavorio, R. (1976). Ultrastructure de quelques stades de la Microsporidie Octosporea muscaedomesticae Flu, parasite de Ceratitis capitata (Wiedemann) (Diptère, Trypetidae). Fournal of Eukaryotic Microbiology 23, 320-328.

Refardt, D., Canning, E. U., Mathis, A., Cheney, S. A., Lafranchi-Tristem, N. J. and Ebert, D. (2002). Small subunit ribosomal DNA phylogeny of microsporidia that infect Daphnia (Crustacea : Cladocera). Parasitology 124, 381-389.

Reynolds, E. S. (1963). The use of lead citrate at high $\mathrm{pH}$ as an electron-opaque stain in electron microscopy. The Fournal of Cell Biology 17, 208-212.

Romeis, B. (1968). Mikroskopische Technik, R. Oldenbourg, München, Germany and Wien, Austria.

Ronquist, F. and Huelsenbeck, J. P. (2003). MrBayes 3: Bayesian phylogenetic inference under mixed models. Bioinformatics 19, 1572-1574.

Stirnadel, H. A. and Ebert, D. (1997). Prevalence, host specificity and impact on host fecundity of microparasites and epibionts in three sympatric Daphnia species. Fournal of Animal Ecology 66, 212-222.

Tautz, D., Arctander, P., Minelli, A., Thomas, R. H. and Vogler, A. P. (2003). A plea for DNA taxonomy. Trends in Ecology and Evolution 18, 70-74.

Thompson, J. D., Gibson, T. J., Plewniak, F., Jeanmougin, F. and Higgins, D. G. (1997). The ClustalX windows interface: flexible strategies for multiple sequence alignment aided by quality analysis tools. Nucleic Acids Research 25, 4876-4882.

Vávra, J. and Larsson, J. I. R. (1999). Structure of the microsporidia. In The Microsporidia and Microsporidiosis (ed. Wittner, M. and Weiss, L. M.), pp. 7-84. ASM Press, Washington, D.C., USA.

Vizoso, D. B. and Ebert, D. (2004). Within-host dynamics of a microsporidium with horizontal and vertical transmission: Octosporea bayeri in Daphnia magna. Parasitology 128, 31-38.

Vizoso, D. B. and Ebert, D. (2005). Mixed inoculations of a microsporidian parasite with horizontal and vertical infections. Oecologia (Berlin) 143, 157-166.

Vizoso, D. B., Lass, S. and Ebert, D. (2005). Different mechanisms of transmission of the microsporidium Octosporea bayeri: a cocktail of solutions for the problem of parasite permanence. Parasitology 130, 501-509.

Zbinden, M., Haag, C. R. and Ebert, D. (2008). Experimental evolution of field populations of Daphnia magna in response to parasite treatment. Fournal of evolutionary Biology 21, 1088-1078. 